\title{
Analysis of the Influence of Organic Corrosion Inhibitors on Corrosion of Reinforcement in Concrete Bridge Structure Under Simulated Field Service Environment
}

\author{
L. Shi, J. Ye, C. C. Chen, Y. Wu, and J. Z. Liu \\ State Key Laboratory of High Performance Civil Engineering Materials, \\ Jiangsu Research Institute of Building Science \\ Jiangsu Sobute New Materials Co., Ltd
}

\begin{abstract}
For concrete bridge projects in marine environments, attention must be paid to the reinforcement corrosion problems caused by chloride intrusion. As kinds of functional admixtures, which can reduce the reinforcement corrosion rate, corrosion inhibitors are becoming very popular in China in new bridge projects. Corrosion inhibitors cover both inorganic and organic inhibitors. Nitrite is representative of inorganic corrosion inhibitors, but its carcinogenicity has hindered its further development. Organic corrosion inhibitors such as small-molecule-based alcohol amine series are becoming the focus of attention. To guide the scientific applications of organic corrosion inhibitors, China is carrying out broad applications technology research. But the evaluation of the influence of organic corrosion inhibitors on the behavior of reinforcement corrosion is mostly carried out in simulated liquids. This method simplifies the actual service environment but ignores the concrete protective layer, the form of chloride intrusion, and environmental effects, which must be considered for the application of organic corrosion inhibitor technology in practical engineering. The experimental work of this paper was conducted on a coastal bridge named Guan He Bridge in China. The influence of organic corrosion inhibitors on the reinforcement corrosion behavior in the concrete bridge structure was investigated considering the conditions of concrete protective layer change, form of chloride intrusion, and different environments through laboratory simulations. Actions and effects of organic corrosion inhibitors were comprehensively evaluated, thereby enriching the application field of organic corrosion inhibitors.
\end{abstract}

\section{INTRODUCTION}

Reinforcement corrosion problems easily occur for concrete bridge structures in marine environments. Jiangsu Province, China, spends 100 million yuan per year on the repairing and strengthening of concrete bridge structures as a result of reinforcement corrosion problems. The use of a corrosion inhibitor is one of the effective measures to reduce the risk of reinforcement corrosion. Reinforcement corrosion inhibitors have 60 years of history, the main products consisting of inorganic (such as nitrites) and organic (such as small-molecule alcohol amines) materials. Inorganic corrosion inhibitors were widely applied in concrete bridges in the 1990s in China. Now, organic corrosion inhibitors are being used widely (Hangzhou Bay Bridge and Chong Kai Bridge both used organic corrosion inhibitors). The evaluation of the effect of organic corrosion inhibitors is very important for applied technology promotion. Existing methods of evaluation of organic corrosion inhibitors mostly use electrochemical methods, such as EIS, LPR, GPM, half-cell potential method, electrochemical noise method, and constant power law. Some of these evaluation methods are carried out in simulated liquids (simulated pore solution of mortar or concrete) while others are carried out in concrete specimens. In the simulated liquid method, the reinforcement is immersed in a solution with chloride salt and corrosion inhibitors while limiting the ambient temperature, without wetting-drying cycles, and without considering corrosion inhibitor loss. In the methods using concrete specimens, corrosion inhibitors are added to the concrete and the chloride salt penetrates into the specimen from outside through wetting-drying cycles without considering the negative temperature range and the concrete protective layer thickness change. But there is some difference between the two evaluation methods and practical engineering cases. First, the concrete protective layer thickness of different parts of a bridge structure is different and the protective layer may change as a result of attack by the external corrosion medium or physical damage; so the existing evaluation methods are not consistent with an actual project situation. Second, the chloride salt directly mixes and intrudes from outside the existing concrete bridge structure. Although the existing evaluation methods include different chloride intrusion forms, the test conditions are different, so the results are difficult to compare. Third, some concrete structures are in cold areas and so freeze-thaw cycles must be considered, 
but the existing evaluation methods are all carried out at positive temperature ranges so that the guiding role of evaluation results for the project is limited.

The experimental work of this paper was conducted on a coastal bridge named Guan He Bridge in China. The bridge is about $5 \mathrm{~km}$ long and the concrete tower is $167.5 \mathrm{~m}$ high. The concrete tower reinforcement may undergo corrosion. The influence of organic corrosion inhibitors on the corrosion behavior of the reinforcement in the concrete bridge structure was investigated considering the conditions of concrete protective layer change, chloride intrusion form difference, and various environments through laboratory simulations. The comprehensively evaluated results gave some recommendations for the application of organic corrosion inhibitors on this bridge.

\section{EXPERIMENTAL}

\subsection{Materials}

The cement used in this study was type PII 52.5 Portland cement (performance conforms to Chinese standard GB175-2007). Mineral admixtures used in this study were Class II F fly ash (performance conforms to Chinese standard GB/T 1596-2005) and S95 slag (performance conforms to Chinese standard GB/T 18046-2008). The chemical composition of the cementitious material is shown in Table 1.

Table 1. Chemical composition of cementitious material (wt\%).

\begin{tabular}{lcrrrrr}
\hline Sample & $\mathrm{SiO}_{2}$ & $\mathrm{CaO}$ & $\mathrm{MgO}$ & $\mathrm{Fe}_{2} \mathrm{O}_{3}$ & $\mathrm{Al}_{2} \mathrm{O}_{3}$ & $\mathrm{SO}_{3}$ \\
\hline PII 52.5 & 18.00 & 68.10 & 1.55 & 3.94 & 4.29 & 1.11 \\
Portland cement & & & & & & \\
Fly ash & 47.72 & 7.22 & 1.15 & 5.63 & 31.83 & 1.02 \\
Slag & 30.10 & 39.10 & 9.15 & 0.39 & 16.10 & 2.47 \\
\hline
\end{tabular}

The sand fineness modulus was 2.6, and the density of sand was $2650 \mathrm{~kg} / \mathrm{m}^{3}$. The size of crushed basalt coarse aggregate used in this study was between 5 and $31.5 \mathrm{~mm}$. Polycarboxylate superplasticizer (PCA), small-molecule alcohol amine corrosion inhibitors (ZX), and calcium nitrite corrosion inhibitors (CN), as well as carbon steel were used in this study.

\subsection{Concrete mix proportion design}

All the experiments in this study were focused on the C50 concrete tower. The concrete mix proportion is shown in Table 2. In the mix, mineral admixtures were used to enhance the durability of the concrete. Concrete without corrosion inhibitors (C50-control), with small-molecule alcohol amine (C50-ZX), and with calcium nitrite $(\mathrm{C} 50-\mathrm{CN})$ were considered in the mix design. When the concrete specimens with reinforcement were cast, the fresh concrete needed to have the same slump and air content.
Table 2. Concrete mix proportion $\left(\mathrm{kg} / \mathrm{m}^{3}\right)$.

\begin{tabular}{|c|c|c|c|c|c|c|c|c|c|}
\hline \multirow[t]{2}{*}{ Sample } & \multicolumn{6}{|c|}{ Mix proportion $\left(\mathrm{kg} / \mathrm{m}^{2}\right)$} & \multirow[t]{2}{*}{ PCA } & \multirow[t]{2}{*}{$\mathbf{Z X}$} & \multirow[t]{2}{*}{$\mathrm{CN}$} \\
\hline & C & FA & SL & $S$ & $\mathbf{G}$ & W & & & \\
\hline $\begin{array}{l}\text { C50- } \\
\text { control }\end{array}$ & 322 & 46 & 92 & 721 & 1081 & 138 & $\sqrt{ }$ & - & - \\
\hline C50-ZX & 322 & 46 & 92 & 721 & 1081 & 138 & $\sqrt{ }$ & $\sqrt{ }$ & - \\
\hline $\mathrm{C} 50-\mathrm{CN}$ & 322 & 46 & 92 & 721 & 1081 & 138 & $\sqrt{ }$ & - & $\sqrt{ }$ \\
\hline
\end{tabular}

C, cement; FA, fly ash; SL, slag; S, sand; G, coarse aggregate; W, water.

\subsection{Reinforcement corrosion behavior experiment}

In the concrete tower structure, the root concrete undergoes wetting-drying cycles and freeze-thaw cycles, so the research is focused on this area. As shown in Figure 1, specimen 1\# $(10 \mathrm{~mm}$ concrete protective layer thickness) and specimen $2 \#$ (30 mm concrete protective layer thickness) have comparable influence of different corrosion inhibitors on reinforcement corrosion behaviors when the protective layer thickness is changed. Specimen 2\# (chloride salt penetrated from outside) and specimen $3 \#$ (chloride salt mixed directly) have comparable influences of different corrosion inhibitors on reinforcement corrosion behaviors when the chloride intrusion form was different. Specimen 2\# (chloride salt penetrated at positive temperature range) and specimen $4 \#$ (chloride salt penetrated at negative temperature range) have comparable influence of different corrosion inhibitors on reinforcement corrosion behaviors when the environmental temperature was different.

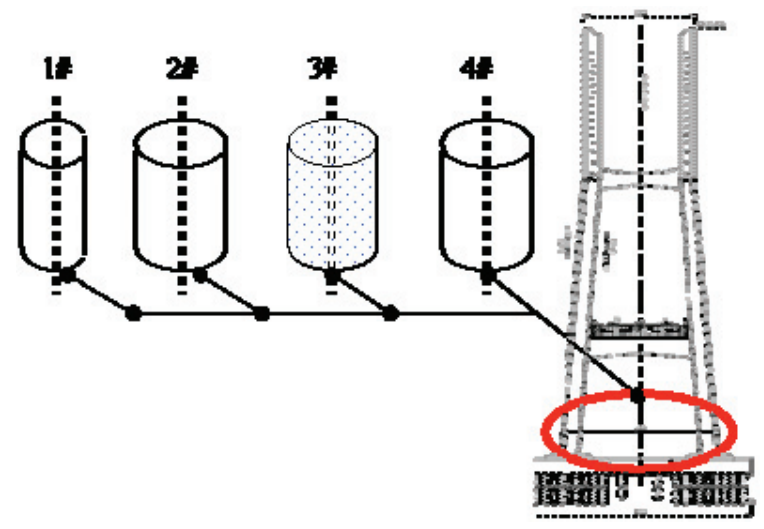

Figure 1. Schematic diagram of concrete specimens simulated in actual tower root service environment.

(a) Influences of different corrosion inhibitors on reinforcement corrosion behavior when the protective layer thickness changed were investigated through a wetting-drying cycle test. The tower concrete specimens were removed after $24 \mathrm{~h}$ and cured under standard conditions for 7 days ( $\mathrm{RH} 96 \%$, temperature $22 \pm 2^{\circ} \mathrm{C}$ ) to simulate the actual concrete structure curing conditions. Then the initial state of the internal reinforcement in the specimen was tested. The 
specimens were immersed in $3.5 \%$ sodium chloride solution for 2 days and then dried in an oven (temperature $60^{\circ} \mathrm{C}$ ) for 2 days. This completes a wetting-drying cycle. The corrosion status of the internal reinforcement in the specimens was tested after a specified number of cycles.

(b) Influences of different corrosion inhibitors on the reinforcement corrosion behaviors considering different chloride intrusion forms were investigated through a wetting-drying cycle test and a hydrostatic immersion test. The wettingdrying cycle test was the same as in part (a). Chloride salt with $3.5 \%$ mass percentage was mixed into the concrete and the cured condition was consistent with the wetting-drying cycle test. The corrosion status of the internal reinforcement in the specimens containing the chloride salt was tested every 4 days (synchronous with wettingdrying cycles).

(c) Influences of different corrosion inhibitors on reinforcement corrosion behaviors considering the environmental temperature difference were investigated through a wetting-drying cycle test and a freeze-thaw cycle test. The wettingdrying cycle test was the same as in part (a). The freeze-thaw cycle test was carried out in a 3.5\% sodium chloride solution (temperature from +20 to $-20^{\circ} \mathrm{C}$ ) according to the Chinese standard GB/T 50082-2009. The corrosion status of the internal reinforcement in the specimens subjected to freeze-thaw cycles was tested after every cycle (synchronous with the wetting-drying cycles).

An electrochemical workstation was used to test the corrosion status of the internal reinforcement in the specimens (Figure 2). The corrosion current density was the key indicator to characterize the reinforcement corrosion behavior and the corrosion inhibitor effect. The current density was tested with the potentiodynamic scanning method (relative to the open-circuit potential, from +10 to $-10 \mathrm{mV}$ ) and obtained by calculation.

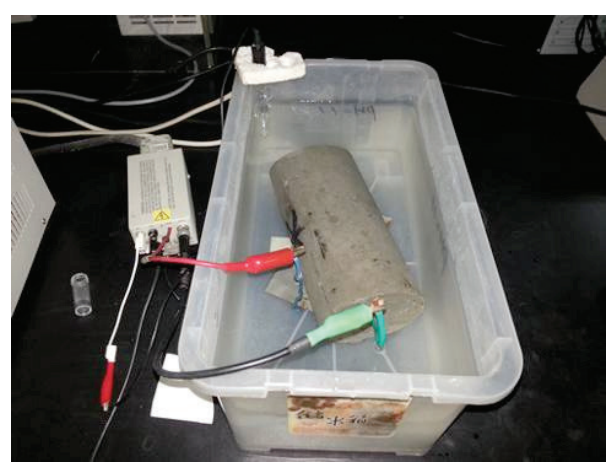

Figure 2. Test equipment for the corrosion status of the internal reinforcement in a specimen.

\section{RESULTS}

Figure 3 illustrates the relationship between the corrosion current density and corrosion age considering different corrosion inhibitors and change in protective layer thickness. The corrosion current density of the reinforcement in concrete $(30 \mathrm{~mm}$ protective layer thickness) without corrosion inhibitors was higher than $0.1 \mu \mathrm{A} / \mathrm{cm}^{2}$ (the current threshold of steel corrosion) after two wetting-drying cycles. When small-molecule alcohol amine and calcium nitrite were added to the concrete, the corrosion current density of the reinforcement decreased. The current threshold of steel corrosion $\left(0.1 \mu \mathrm{A} / \mathrm{cm}^{2}\right)$ was reached after four wetting-drying cycles for organic corrosion inhibitors and after more than five wetting-drying cycles for inorganic corrosion inhibitors. There was a significant impact of the wetting-drying cycles on the corrosion current density of reinforcement in concrete when the protective layer thickness decreased to $10 \mathrm{~mm}$. The corrosion current density of reinforcement in concrete (10 $\mathrm{mm}$ protective layer thickness) without corrosion inhibitors was higher than $0.1 \mu \mathrm{A} / \mathrm{cm}^{2}$ after only one wetting-drying cycle. For reinforcement in concrete with organic and inorganic corrosion inhibitors, the corrosion current density increased up to $0.1 \mu \mathrm{A} / \mathrm{cm}^{2}$ after two wetting-drying cycles.

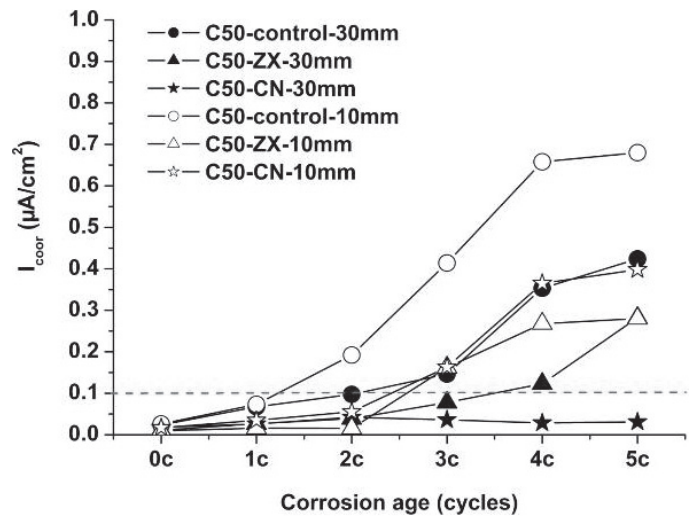

Figure 3. Relationship between corrosion current density $\left(I_{\text {corr }}\right)$ and corrosion age (wetting-drying cycles) from 0c (initial) to $5 \mathrm{c}$ (five cycles). Change in corrosion inhibitor and change in protective layer thickness were considered. Concrete mix proportions and test methods are as listed in Table 2 and Section 2.3(a).

The corrosion current density increase of the reinforcement for different protective layer thicknesses of concrete (without corrosion inhibitors and with different corrosion inhibitors) was different after five wetting-drying cycles. There was a 17-fold increase in the corrosion current density of reinforcement for $30 \mathrm{~mm}$ protective layer thickness of concrete without corrosion inhibitors, whereas it increased by 25.4 -fold when the protective layer thickness was reduced to $10 \mathrm{~mm}$. For reinforcement in concrete with organic corrosion inhibitors, the corrosion current density 
increase did not change significantly with the protective layer thickness (the values were between 24 and 29 times). The corrosion current density increase for reinforcement in concrete with inorganic corrosion inhibitors changed substantially. The increase was 0.7 times when the protective layer thickness was $30 \mathrm{~mm}$, which went up to 22.8 times when the protective layer thickness was decreased to $10 \mathrm{~mm}$.

As illustrated in Figure 4, the reinforcement corrosion behaviors were significantly inhibited by corrosion inhibitors when the chloride salt penetrated from outside. For the situation where the chloride salt was mixed directly, the corrosion current density increase for the reinforcement in concrete (without or with different corrosion inhibitors) did not significantly change with aging synchronous with the wetting-drying cycles. The inhibitory effects of corrosion inhibitors on reinforcement corrosion behavior were widely different due to the different chloride intrusion form.

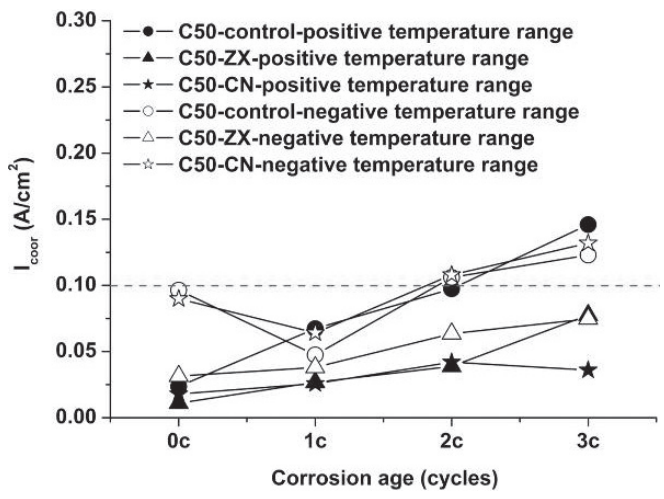

Figure 4. Relationship between corrosion current density $\left(I_{\text {corr }}\right)$ and corrosion age (wetting-drying cycles) from $0 \mathrm{c}$ (initial) to $5 \mathrm{c}$ (five cycles). Change in corrosion inhibitor and change in chloride intrusion form were considered. Concrete mix proportions and test methods as listed in Table 2 and Section 2.3(b).

Figure 5 illustrates the relationship between corrosion current density and corrosion age, considering corrosion inhibitor difference and environmental temperature difference. The corrosion current density value of the reinforcement in concrete without corrosion inhibitors was $0.15 \mu \mathrm{A} / \mathrm{cm}^{2}$ after three wetting-drying cycles in the positive temperature range, whereas it was $0.12 \mu \mathrm{A} / \mathrm{cm}^{2}$ after three freeze-thaw cycles in the negative temperature range. Positive and negative temperatures had no significant effect on the corrosion current density of reinforcement in concrete without corrosion inhibitors. Similarly, environmental temperature difference had no significant effect on the corrosion current density of reinforcement in concrete with organic corrosion inhibitors. The corrosion current density of reinforcement in concrete with small-molecule alcohol amine was $0.08 \mu \mathrm{A} / \mathrm{cm}^{2}$ after three wettingdrying cycles in the positive temperature range, whereas it was $0.07 \mu \mathrm{A} / \mathrm{cm}^{2}$ after three freeze-thaw cycles in the negative temperature range. But the corrosion current density of reinforcement in concrete with inorganic corrosion inhibitors increased significantly in the negative temperature range. The current density with calcium nitrite was $0.04 \mu \mathrm{A} / \mathrm{cm}^{2}$ after three wetting-drying cycles in the positive temperature range, whereas it increased to $0.13 \mu \mathrm{A} / \mathrm{cm}^{2}$ after three freeze-thaw cycles in the negative temperature range (almost the same as the control sample).

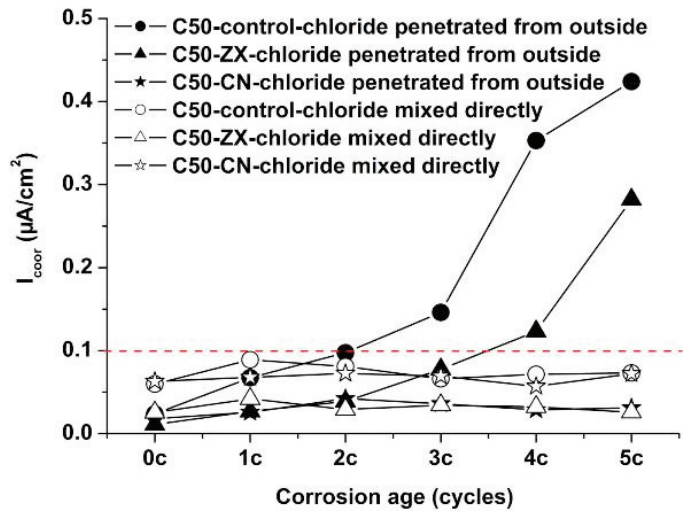

Figure 5. Relationship between corrosion current density $\left(I_{\text {corr }}\right)$ and corrosion age (wetting-drying cycles) from 0c (initial) to $3 \mathrm{c}$ (three cycles). Corrosion inhibitor difference and environmental temperature difference were considered. Concrete mix proportions and test methods as listed in Table 2 and Section 2.3(c).

\section{DISCUSSION}

\subsection{Influence of corrosion inhibitors on reinforcement corrosion behavior considering change in the protective layer thickness}

Previous studies have shown that a decrease in the protective layer thickness of a concrete bridge structure makes the path for chloride ions to intrude into the concrete shorter. Thus, the corrosion current density of reinforcement in concrete with $10 \mathrm{~mm}$ protective layer thickness was higher than that with $30 \mathrm{~mm}$ protective layer thickness. Inorganic corrosion inhibitors (calcium nitrite) are anodic corrosion inhibitors. They make the reinforcement surface form a dense iron oxide film, thereby suppressing the anode reaction. The effect of rust due to inorganic corrosion inhibitors is closely related to the $[\mathrm{Cl}-] /\left[\mathrm{NO}_{2}\right]$ values. A smaller $\left[\mathrm{Cl}^{-}\right] /\left[\mathrm{NO}_{2}\right]$ value will have a better rust effect. The dosage of calcium nitrite $(2 \%$ of the mass) was constant. The chloride ion intrusion to the interior of the concrete increased when the concrete protective layer thickness decreased, and so the $\left[\mathrm{Cl}^{-}\right] /$ $\left[\mathrm{NO}_{2}\right]$ value increased. On the other hand, inorganic corrosion inhibitors show obvious dissolution phenomena under flowing water conditions (wettingdrying cycles are flowing water accelerating test). The reduction in concentration of the inorganic corrosion inhibitor caused the $[\mathrm{Cl}-] /\left[\mathrm{NO}_{2}\right]$ values to increase. In 
addition, $\mathrm{OH}$ ions are essential for inorganic corrosion inhibitors to give rise to the rust effect. The carbonation of concrete was accelerated during the wetting-drying cycles. There were fewer $\mathrm{OH}^{-}$ions in concrete with a $10 \mathrm{~mm}$ protective layer than with a $30 \mathrm{~mm}$ protective layer so that the protection reactions did not work very well. Therefore, the corrosion current density of reinforcement in concrete with inorganic corrosion inhibitors increased dramatically when the protective layer thickness decreased.

Organic corrosion inhibitor molecules (small-molecule alcohol amines) diffuse into the reinforcement surface by the vapor and liquid phases in the pore structure of concrete. Such inhibitor molecules push out the adsorbed water molecules and chloride ions on the reinforcement surface and form a "chemical-physical combination film" to protect the reinforcement. Organic corrosion inhibitors not only have a "filming" function but also have a "plug holes" function. The calcium ions in cement paste combine with other groups except amine to form insoluble calcium salts and block the capillary pores so that the concrete corrosion resistance is enhanced. The chloride ion diffusion coefficient test results show that the chloride ion diffusion coefficient of the tower concrete with organic corrosion inhibitors decreased from $5.35 \times 10^{-12}$ to $4.12 \times 10^{-12} \mathrm{~m}^{2} / \mathrm{s}$ (a decrease of $23 \%$ ). However, the inorganic corrosion inhibitors did not decrease the chloride ion diffusion coefficient of the tower concrete. As the concrete protective layer thickness was reduced from 30 to $10 \mathrm{~mm}$, the amount of chloride ion intrusion might not change significantly so that corrosion current density with organic corrosion inhibitors also did not change obviously.

\subsection{Influence of corrosion inhibitors on reinforcement corrosion behavior considering change in chloride intrusion form}

For hardened concrete without chloride mixed directly, free chloride ions penetrating from outside are the main cause of reinforcement corrosion. When concrete structures were subjected to wetting-drying cycles, the rust effect of different corrosion inhibitors was different. The reasons for the differences in rust effect are explained in Section 4.1.

Mineral admixtures and double mixed techniques were used in the tower concrete mix proportion design. Mineral admixtures show a large adsorption of chloride ions. When the chloride salt was mixed directly into the concrete, a large number of chloride ions were curable as the hydration progressed and the free chlorine ions were relatively few so that the initial corrosion current density of the reinforcement did not exceed $0.1 \mu \mathrm{A} / \mathrm{cm}^{2}$ (which is the current threshold of steel corrosion). Hydrostatic immersion test instead of wetting-drying cycles was used for concrete specimens with chloride mixed directly. The inorganic corrosion inhibitor dissolution was not obvious and the $\left[\mathrm{Cl}^{-}\right] /\left[\mathrm{NO}_{2}\right]$ values almost remained the same, so the rust effect of inorganic corrosion inhibitors was good. For organic corrosion inhibitors, the "chemicalphysical combination film" protected the reinforcement against chloride ion erosion, so the corrosion current density of the reinforcement did not change in the shorter evaluation period.

\subsection{Influence of corrosion inhibitors on reinforcement corrosion behavior considering environmental temperature difference}

Diffusion is very important for inorganic corrosion inhibitors to enable them to protect reinforcement in concrete. When the temperature decreases, the rate of diffusion of calcium nitrite was affected (when the temperature decreased by $14^{\circ} \mathrm{C}$, the diffusion rate reduced by $50 \%$ ). Calcium nitrite would lower the freezing point of concrete capillary pore solution to $-25^{\circ} \mathrm{C}$ and the capillary pore solution might not be frozen during the freeze-thaw cycles in the negative temperature range (from +20 to $-20^{\circ} \mathrm{C}$ ) so that the chloride ions outside (chloride salt also lowers the freezing point of the test solution) could penetrate into the concrete and the calcium nitrite could dissolve out of the concrete easily. All these factors caused the corrosion current density of the reinforcement in concrete with inorganic corrosion inhibitors to increase significantly during the freeze-thaw cycles. The "Corrosion inhibitor for steel in concrete" report also pointed out that deterioration of concrete (such as concrete undergoing freeze-thaw cycles) would increase the dissolution of nitrite and reduce the reinforcement rust efficiency.

Organic corrosion inhibitor molecules diffused onto the reinforcement surface by vapor and liquid phases but did not affect the freezing point of the concrete internal and environment solution. As illustrated in Section 4.1, organic corrosion inhibitors enhanced the concrete corrosion resistance so that the chloride ions diffused with difficulty into concrete to erode the reinforcement. Even though the internal capillary pore solution froze, organic corrosion inhibitors could also migrate to the reinforcement surface by vapor to protect the reinforcement so that the corrosion current density did not increase obviously.

\section{CONCLUSIONS}

- Concrete protective layer thickness change must be considered when assessing the corrosion inhibitors' rusting effect. The rust effect of organic corrosion inhibitors was more stable and durable when the protective layer thickness of the structure changed compared to that of inorganic corrosion inhibitors. 
- For concrete structures in different environments, a change in chloride intrusion form had obvious influences on the corrosion inhibitor rust effect. Organic corrosion inhibitors were better in delaying reinforcement corrosion effect than inorganic corrosion inhibitors under alternating wet and dry conditions. The reinforcement corrosion behaviors in concrete with different corrosion inhibitors were almost the same when the chloride salt was mixed directly into concrete under short-term hydrostatic immersion conditions.

- Influences of the different corrosion inhibitors on reinforcement corrosion behaviors when considering environmental temperature difference were different. Organic corrosion inhibitors had more obvious advantages than inorganic corrosion inhibitors in the freeze-thaw environment.

The following are the recommendations for organic corrosion inhibitor application technology in the Guan He Bridge (Figure 6):

- Organic corrosion inhibitors should be used in a concrete structure where the protective layer is thin or the protective layer is easily damaged during service.

- Organic corrosion inhibitors should be used to protect the reinforcement in the concrete structure which may be subjected to wetting-drying and freeze-thaw cycles.

Organic and other kinds of corrosion inhibitors can be used in a concrete structure that is in service under water for a long time if the water is stationary instead of flowing.

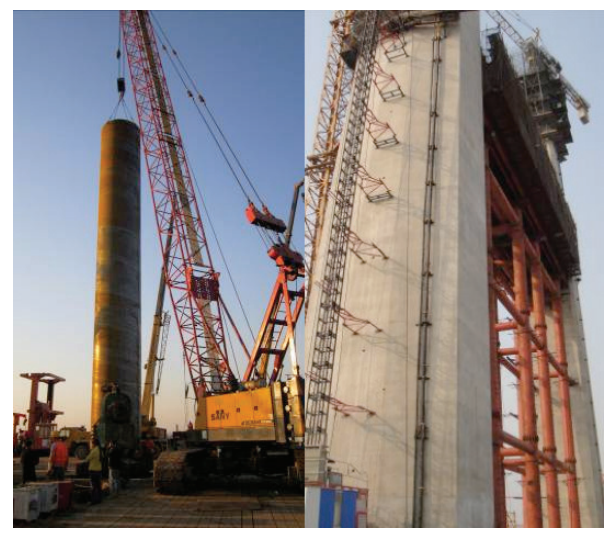

Figure 6. Concrete tower of Guan He Bridge in which organic corrosion inhibitors were used.

\section{ACKNOWLEDGMENTS}

This work was financially supported by the National Science and Technology Support Program (grant no. 2010BAE27B02-2) and the Jiangsu Transportation
Scientific Research Projects. Research achievements have guided the application of organic corrosion inhibitor technology in the Guan He Bridge. The authors would like to thank their collaborators from the China Communications Construction Co. Ltd.

\section{REFERENCES}

Chen, S. (2005). Rehabilitation technology of reinforced concrete. Corrosion and Protection, 26(1), 39-41. [in Chinese].

Chen, X., Huang, T., \& Shi, Z. (2008). Study and application of the anti-corrosion-\&-rust concrete in the oceanic freeze-thaw surroundings. Research and Application of Building Materials, 11, 002. [in Chinese].

China Industry Anticorrosion Technology Association. (2009). Comment on the "Corrosion Control Measurements for Hangzhou Bay Bridge," CICC 2009, 30-47. [in Chinese]

Cigna, R., Andrade, C., Nürnberger, U., Polder, R., Weydert, R., \& Seitz, E. (2003). Corrosion of steel in reinforced concrete structures. (European cooperation in the field of scientific and technical research). Brussels, Belgium: COST.

Elsener, B. (2001). Corrosion inhibitor for steel in concrete. European Federation of Corrosion Publications No. 35. Oxford, England: EFC.

Glass, G. K. (1995). An assessment of the coulostatic method applied to the corrosion of steel in concrete. Corrosion Science, 37(4), 597-605.

Glass, G. K. (1997). The analysis of potentiostatic transients applied to the corrosion of steel in concrete. Corrosion Science, 39(9), 1657-1663.

Hong, N. (2004). Chloride corrosion durability of concrete structures and the environment. Chinese Sixth Symposium on Durability of Concrete Structures, 5. [in Chinese].

John, P. B. (2002). The use of permanent corrosion monitoring in new and existing reinforced concrete structures. Cement and Concrete Composites, 24, 27-34.

Legat, A., Leban, M., \& Bajt, Z. (2004). Corrosion processes of steel in concrete characterized by means of electrochemical noise. Electrochimica Acta, 49, 2741-2751.

Lianga, H., Lib, L., Poorc, N. D., \& Sagüé, A. A. (2003). Nitrite diffusivity in calcium nitrite-admixed hardened concrete. Cement and Concrete Research, 33, 139-146.

Liu, Z., Miao, C., Sun, W., et al. (2010). The effect of migratory corrosion inhibitors on the durability of chloride-contaminated reinforced concrete-long term effect. Morphological and Mechanisms Analysis. Journal of Chinese Ceramic Society, 38(7).

Liu, J., Li, L., Shan, W., Li, Y., \& Ge, H. (2004). Nitrite corrosion inhibitor in reinforced concrete. Concrete 
Admixture Technology and its Applications, 6, 320-325. [in Chinese].

Liu, Z., Miao, C., \& Sun, W. (2010). Effect of surface applied $\mathrm{MCls}$ and sealants on the durability of reinforced concrete in rigorous chloride conditions. The Seventh International Symposium on Cement and Concrete, Jinan, China, 5.

Martin-Perez, B., Zibara, H., Hooton, R. D., \& Thomas, M. D. A. (2000). A study of the effect of chloride binding on service life predictions. Cement and Concrete Research, 30, 1215-1223.

Newton, C. J. (1988). A galvanostatic pulse technique for investigation of steel corrosion in concrete. Corrosion Science, 28(11), 1051-1074.

Xu, Q., Yin, H., \& Wang, Q. (2004). Build a mathematical model of penetration-Donghai Bridge structural concrete and concrete durability strategies $\mathrm{Cl}$. The durability of concrete structures in coastal areas and the design method of the Sixth National Science and Technology Forum and the Durability of Concrete Symposium, Vol. 5 (pp. 17-23). [in Chinese]

Xu, X., \& Liu, B. (2003). A surrey of the research on reinforcement rustiness in concrete. Journal of Sichuan University of Science and Technology, 22(3), 83-85. [in Chinese].
Xu, Y. (2002). Migrating corrosion inhibitor-a new development of corrosion inhibitors for steel bar in concrete. Journal of the Chinese Ceramic Society, 30(1), 94-101. [in Chinese].

Yan, P., \& Cui, L. (1999). Galvanostatic pulse method in time domain and frequency domain to determine the corrosion status of rebar in concrete. Journal of Building Materials, 2(3), 199-205. [in Chinese].

Yu, L., Liu, Z., \& Sun, H. (2012). Extravasation of the rust inhibitor mixed with salt for chlorine in concrete reinforcement corrosion rate on pilot study. Eighth National Symposium on Durability of Concrete, Vol. 9 (pp. 505-509). [in Chinese]

Zhang, X., Zhou, Q., \& Chen, L. (2004). Corrosion inhibitor application development overview. Construction Technology, 6, 52-53. [in Chinese].

Zhu, J. Causes corrosion of steel bridges in coastal areas analysis and protection measures. Retrieved from http://wenku.baidu.com/link?url=Npvv6Tq903pPTJ LsjhnMGPUTfXsC6EGQ3gDcwpoD7zRroUiSTKHL m9tUFlbgKDfhxBUhrv5538FMt7BtnZFY _ fYmvV7A6r-KB4xVb4Y2h3 